\title{
Intensive Magnitudes, Temporality, and Sensus Communis in Kant's Aesthetics
}

\author{
Kenneth Noe
}

\begin{abstract}
I offer a critique of Melissa Zinkin's reading of Kant's analysis of aesthetic judgment. She argues that in judgments of taste the imagination is freed from its determinate relation with the understanding because the form of intuition in which beauty is apprehended is different from the form of intuition employed in determinate judgment. By distinguishing between an extensive and intensive form of intuition, this interpretation is able to explain why the apprehension of beauty cannot be subsumed under a concept. But I contest Zinkin's identification of the sensus communis with this intensive form of intuition. I then substantiate two interrelated claims: (1) that we can account for the genesis of the sensus communis by distinguishing between an intensive and an extensive form of time, and (2) that we can avoid making the sensus communis atemporal by showing that it resides within an intensive form of time as a condition for its possibility, thereby structuring Kant's account of the sensus communis securely within the critical framework.
\end{abstract}

\section{INTRODUCTION}

$\mathrm{K}$ ANT'S DISCUSSION of the sensus communis as that which grounds the normativity of judgments of taste presents a genuine difficulty for interpreting the role of the sensus communis within the overall critical framework. As is well known, the critical turn states that all judgments in general (theoretical, practical, aesthetic, teleological) must be recognized and accounted for as arising from within a cognitive or otherwise structurally subjective point of view. The goal here is to curb the pretensions of the claims of traditional metaphysics, a realm that for Kant represents a graveyard populated by judgments that transcend the subject's spatio-temporal situatedness. It would take little argument to reveal that this critical injunction applies no less to claims made concerning the role of the sensus communis in grounding the normativity of judgments of taste. This means that, contrary to the way in which Kant often seems to speak of the sensus communis-namely, as a subjective principle that must be presupposed in all judgments of taste-it is something that must be accounted for within the subjective standpoint if we are to remain within the critical parameters. What, then, is the nature of the sensus communis and how are we to account for it within the critical philosophy?

Among Kant's many descriptions of the sensus communis, perhaps the most nebulous occurs in section 20 of the Critique of Judgment where it is first mentioned. Here Kant describes it as "the effect arising from the free play of our cognitive 
powers" (5:238, emphasis added). ${ }^{1}$ Moreover, just prior to this passage Kant says that what he means by "common sense" is not "the common understanding that is sometimes also called common sense (sensus communis), for the latter judges not by feeling but always by concepts, even though these concepts are usually only principles conceived obscurely" (5:238). And later Kant claims that

taste can be called sensus communis more legitimately than can sound understanding, and that the aesthetic power of judgment deserves to be called a shared sense more than does the intellectual one.... We could even define taste as the ability to judge something that makes our feeling in a given presentation universally communicable without mediation by a concept."

To this passage he appends the footnote: "Taste could be called a sensus communis aestheticus, and common understanding a sensus communis logicus" (5:295/n, emphasis added).

Given these claims, it follows that for Kant the sensus communis is (1) not only a presupposition that grounds the normativity of judgments of taste but is, perhaps more interestingly, the effect or product of what Kant calls "the mental state in which we are when imagination and understanding are in free play (insofar as they harmonize with each other as required for cognition in general)" (5:217-18). We should also note that (2) the sensus communis, like a judgment of taste itself, is based on "feeling rather than concepts, though nonetheless with universal validity, what is liked or disliked" (5:238). And (3) the sensus communis is more properly universally shared than the cultivated understanding and refers to man's merely "sound" but not yet refined intellectual capacity. Kant says that it is something shared by all human beings insofar as we can call them human beings at all. It is "a power to judge that in reflecting takes account (a priori), in our thought, of everyone else's way of presenting something, in order as it were to compare our own judgment with human reason in general and thus escape the illusion that arises from the ease of mistaking subjective and private conditions for objective ones" (5:293). In this sense, it is more appropriate to call the sensus communis a "sense of community" than a "common sense," which, as Kant observes, tends to refer to a sense of common understanding.

If the sensus communis is something that is felt and shared (and thus more properly universal than the refined intellect), then we would do well to ask by what form the sensus communis is presented. How is the sensus communis, in Kant's words, the effect or product of the free play of the imagination and the understanding expressed in judgments of taste? If it is true that the critical turn requires that all sensations and feelings have some form of sensibility, then there must be some form of intuition that makes the subjectively universal feeling of the sensus communis possible. In a

\footnotetext{
${ }^{1}$ Throughout this paper, all direct references to Kant's text are given parenthetically. All references to Critique of the Power of Judgment shall employ the standard Akademie pagination and refer to the Werner S. Pluhar translation of the text (Indianapolis: Hackett, 1987). I will, however, refer to the title as given by Paul Guyer and Eric Matthews in their translation of Kant's third Critique (New York NY: Cambridge Univ. Press, 2001) since I think that this translation of the title is superior to Pluhar's rendering.
} 
recent article, Melissa Zinkin ${ }^{2}$ touches on precisely this issue when arguing that the imagination is not restricted to determinate concepts in judgments of taste because the form in which the imagination apprehends the manifold is different from that of objective cognition. She argues that in contrast to properly cognitive judgments, in which the manifold is intuited in an extensive form of intuition, the apprehension of beauty - from which the judgment of taste follows - is intuited in an intensive form, which prevents the understanding from applying a determinate concept. She further argues that it is in fact the sensus communis that is this intensive a priori form of sensibility on which the normativity of judgments of taste is based. Finally, she argues that by understanding the sensus communis as an a priori form of sensibility it becomes possible to account for three of the distinctive features of judgments of taste outlined by Kant: (1) that they are not determined by a concept; (2) that from them arises the special kind of pleasure of beauty; and (3) that they make a claim to subjective yet universal validity.

In what follows, I offer a critique of Zinkin's interpretation of the sensus communis as an a priori form of intuition. Setting aside the properly textual issue that Kant never refers to it as a form of intuition (and in fact never refers to any forms of intuition other than space and time), the more important systematic issue is that for Kant "common sense" is not a particular faculty at all, as it would be for a classical empiricist, but rather a normatively binding arrangement of faculties that obtains as either a law-governed determinate epistemic or practical accord or as a non-lawgoverned "inner feeling of a purposive state of mind" in aesthetic experience (5:296). Contra Zinkin, I thus argue that the sensus communis is itself not immediately but only reflectively presented to the subject by taking seriously Kant's claim that it is the effect or product of the free play of imagination and understanding, and is rather based on a more primordial temporal orientation (i.e., a form of intuition) that can account for the very genesis of the sensus communis or a "sense of community." My argument proceeds as follows: I first rehearse Zinkin's argument that in judgments of taste the imagination is not restricted to its determinate relation to the understanding because the intuition in which beauty is apprehended is not extensive but rather intensive in form. With Zinkin, I claim that by distinguishing between an extensive and intensive form of intuition, this interpretation is able to explain why the apprehension of beauty cannot be subsumed under a concept. While this initial insight seems perfectly plausible and is indeed successful in resolving the interpretive issues she mentions, I contest Zinkin's further claim that it is precisely the sensus communis that represents this intensive form of intuition. In contrast to Zinkin's reading, I then attempt to substantiate two interrelated claims. First, that we can account for the genesis of sensus communis by distinguishing between an intensive (i.e., aesthetic) form of time in which an indeterminate sense of past, present, and future are fully integrated intensively and an extensive (i.e., successive) form of time in which the past, present, and future are exhibited in a determinate, chronological, and linear succession. Second, that we can avoid the potential pitfall

\footnotetext{
${ }^{2}$ Melissa Zinkin, "Intensive Magnitudes and the Normativity of Taste" in Aesthetics and Cognition in Kant's Critical Philosophy, ed. Rebecca Kukla (New York NY: Cambridge Univ. Press, 2006), pp. $138-61$.
} 
of making the sensus communis into something atemporal by showing that it resides within an intensive form of time as a condition for its possibility, thereby structuring Kant's account safely within the critical framework. ${ }^{3}$

\section{KANT'S DISTINCTION BETWEEN INTENSIVE AND EXTENSIVE MAGNITUDES}

Before moving into a discussion of the intensive form of time, we must first briefly examine Kant's more general distinction between intensive and extensive magnitudes. Our discussion in this section will follow Zinkin's discussion rather closely as a way to ground the analysis of the extensive and intensive forms of time. The latter, as I will argue against Zinkin, provides the transcendental condition of the possibility of the sensus communis.

Kant gives the most extended treatment of extensive and intensive magnitudes in his analyses of the Axioms of Intuition and the Anticipations of Perception in the Critique of Pure Reason. Their difference resides in the differing logical priorities given to a part and its relation to the whole. On the one hand, an extensive magnitude is one "in which the presentation [Vorstellung] of the parts makes possible the presentation [Vorstellung] of the whole (and therefore necessarily precedes the latter)" (A162). ${ }^{4}$ Kant gives the example of a line, which of course cannot be represented without first drawing it out, i.e., by successively producing all the parts as prior to the totality of the line itself. ${ }^{5}$ An extensive magnitude is a measure in which the parts precede the whole, the latter being an additive sum of its parts. Kant's example shows that length is therefore an extensive magnitude. On this point, Zinkin

${ }^{3}$ By this statement I do not mean to suggest that Zinkin's view implies that the sensus communis is atemporal. The issue that I am addressing here is that of establishing the critical parameters of the sensus communis, which, as a ground of the normativity of judgments of taste and as a universal feeling that is felt and shared by all judging subjects, must be accounted for within the spatio-temporal parameter's of Kant's transcendental idealist framework. This requires determining the nature of the spatio-temporal forms of sensibility by which the feeling of the sensus communis is presented, which (I argue) are intensive in their form. One reason that Zinkin's view is mistaken is that for Kant sensus communis always indicates a relationship among the faculties rather than a particular faculty (as traditionally conceived). Whether or not the adoption of the latter position implies that the sensus communis is atemporal is not a claim that I am prepared to stake in this paper.

${ }^{4}$ All citations of Kant's Critique of Pure Reason are located by reference to the pagination of the first (A) edition and the second (B) edition, and refer to the Paul Guyer and Allen Wood translation (New York NY: Cambridge Univ. Press, 1998). For the sake of consistency I will amend the translation to conform to Pluhar's rendering of "presentation" (Vorstellung) and "exhibition" (Darstellung) since (1) my argument depends heavily on this distinction and (2) a good case can be made for the view that "representation" should be jettisoned in favor of "presentation" in the rendering of Vorstellung since this term does not explicitly on its own connote a repetition or reproduction (but rather makes them possible in the first place). While the connotations between Vorstellung and Darstellung overlap in ordinary German parlance, the distinction within Kant's text can be explained briefly in the following way. On the one hand, when the imagination is working with determinate concepts under the legislation of the understanding, it generates a determinate "presentation" (Vorstellung) that enables the cognition of objects. On the other hand, when the imagination is working without the mediation of a concept, the imagination generates an "exhibition" (Darstellung) that results in the free play of the imagination that is the centerpiece of Kant's analysis of the experience of beauty in the third Critique. In addition, my own references to these concepts will reflect Pluhar's usage.

${ }^{5}$ A162/B203. Cf. Zinkin, p. 142. 
draws out "the essential characteristics of extensivity: homogeneity and additivity," the first being the quality of having a uniformity throughout, and the second being the capability of its being quantified in terms of the addition of units that represent its parts. ${ }^{6}$ Simply put, the defining feature of an extensive magnitude is that it is represented as a collection or sum of its parts, the totality being measured as an aggregate of its parts.

Intensive magnitudes, on the other hand, are a bit trickier. As Paul Guyer has made clear, intensive magnitudes present a rather problematic concept for Kant ${ }^{7}$ (at least within the context of the first Critique) since Kant's analysis of intensity seems to be of empirical rather than a priori origin. In contrast to extensive magnitudes, under which Kant classifies all appearances, as determinations within space and time, intensive magnitudes are that under which mere sensations, i.e., immediate qualities, are exhibited (dargestellt) to the subject (A162/B202, A166/B207). Kant writes that

[S]ince sensation in itself is not an objective presentation [Vorstellung], and in it neither the intuition of space nor that of time is to be encountered, it has, to be sure, no extensive magnitude, but yet it still has a magnitude (and indeed through its apprehension, in which the empirical consciousness can grow in a certain time from nothing $=0$ to its given measure), thus it has an intensive magnitude, corresponding to which all objects of perception, insofar as they contain sensation, must be ascribed an intensive magnitude, i.e., a degree of influence on sense. (A166/B208)

This brute and immediate apprehension in sensation does not take place in a series of successive syntheses but rather in single, unified flows of relative duration and intensity. Furthermore, as Kant observes, since every sensation is capable of either growth or diminution (which, as Guyer observes, is not akin to the flickering of a light switch on and off but rather indicates gradations or degrees) what we are presented with in intensive magnitudes is rather "a continuous nexus of many possible intermediate sensations, whose difference from one another is always smaller than the given one and zero, or complete negation" (A168/B210). For Kant, the degrees and gradations of real sensations are not apprehended through a successive synthesis, i.e., from parts to the whole (extensively) but "can only be apprehended as a unity" since the presentation is a "multiplicity" (Vielheit), as opposed to an extensive "manifold" (Mannigfaltigkeit), that can "only be represented through approximation to negation $=0$ " (A168/B210). In other words, intensive magnitudes are measured by the degrees that they exhibit, in contrast to extensive magnitudes, whose measure of the whole comes from externally related units that form an aggregate.

Kant illustrates the concrete meaning of intensive magnitudes by referring to money as a measure of silver, the latter of which represents an intensive magnitude whose value ${ }^{8}$ is measured only with reference to itself. Kant writes:

${ }^{6}$ Zinkin, p. 141.

${ }^{7}$ Paul Guyer, Kant (New York NY: Routledge, 2006), p. 103.

${ }^{8}$ It should be noted that in Kant's day the concept of monetary or economical value did not carry the same meaning that economical value does today since at that time economics was not quantified in the same manner as it is today. This historical contingency allows Kant to illustrate the difference between extensive and intensive magnitudes through the example of the difference between silver and its monetary representation, 
If I call thirteen dollars a quantum of money, I do so correctly insofar as I mean an amount of a mark of silver, which is to be sure a continuous magnitude, in which no part is the smallest but each part could constitute a coin that would always contain material for smaller ones. But if by the term 'thirteen round dollars' I mean so many coins (whatever their amount of silver might be), then it would not be suitable to call this a quantum of dollars, but it might instead be called an aggregate, i.e., a number of coins. (A170/B212) ${ }^{9}$

Kant's example here is useful for a number of reasons. First, it illustrates quite well the difference between intensive and extensive magnitudes. On the one hand, money is itself not a continuous quantum but an additive sum of predetermined units. On the other hand, silver, which if broken into smaller pieces or clumped together in larger pieces, will have a value that is not representable by discrete units but only on a continuous scale. While money is an additive value, silver is a "flowing" value, ${ }^{10}$ as it were, a value that is measured only with reference to itself. Second, Kant's example illustrates that in an important sense, extensive magnitudes depend upon intensive magnitudes. Ultimately, the value of thirteen dollars will come down to the amount of silver that it represents, such that in other words, no part has actual value without reference to the whole as a prior intensive unity. Lastly, Kant's example illustrates that extensive magnitudes are derived from the more primary intensive magnitudes, the dollars being measures of silver that are divided according to the presumed worth of the whole.

Kant's distinction between extensive and intensive magnitudes, then, presents two forms of a unified relation between the parts and the whole. The former consists of a relation in which the parts precede the whole, where unity is the result of a successive synthesis of parts. The latter consists of a relation in which the whole precedes the parts, a relation from which parts (or degrees or gradations of measure) are derived from an originary unity. In sum, while the essential features of extensive magnitudes seem to be additivity and homogeneity, the essential features of intensive magnitudes appear to be derivability and variation. It bears noting that this is a point neglected by Zinkin's discussion.

With respect to these two relations of parts to the whole, Zinkin observes that Kant describes both space and time as extensive magnitudes. Since both space and

but in our time the example is perhaps dated, given our contemporary understanding of monetary value in which the value of currency is no longer simply dependent upon a predetermined measure of precious metals.

${ }^{9} \mathrm{Cf}$. Zinkin, pp. 142-43.

${ }^{10}$ Here one might object that I am confusing a "flowing" quantity with an intensive quantity, where the former refers to an indeterminate quantity that has parts (just those that are not very well defined and blend into each other) while the latter refers to a kind of determination that can be measured only by degrees that do not correlate to parts. I am not interested in strictly correlating intensive quantity with the associated concepts of aesthetic experience, sensus communis, or intensive time, which are more properly qualitative than quantitative (though this correlation could perhaps be argued for). I am rather concerned with introducing the general characteristics of intensity and its distinction from extensity. As it so happens, Kant's discussion of intensity in the first Critique takes place in terms of intensive quantities, but he does not hesitate to describe them as "flowing" either, as evidenced by the following passage: "Magnitudes of this sort can also be called flowing [fließende], since the synthesis (of the productive imagination) in their generation is a progress in time, the continuity of which is customarily designated by the expression 'flowing' ('elapsing')" (A170/B211-212). 
time are extensive, i.e., additive and homogenous, everything within space and time ends up being quantified numerically. ${ }^{11}$ While it is certainly true that the measure of extensive space and time is number, it remains to be seen whether or not, for Kant, space and time can only be represented extensively, i.e., as the addition of parts that form a whole. Indeed such an assumption appears to be operating throughout Zinkin's entire argument. ${ }^{12}$ More specifically for the interests of our present analysis, the case must be made that extensive time is only one possible representation of time itself. For Kant, since there are both extensive and intensive dimensions to temporality, the sensus communis on which the normativity of judgments of taste is based depends on this latter sense of temporality as a condition for the possibility of the intensive feeling of community.

Now in the Transcendental Aesthetic there are certainly places where Kant maintains that space and time are extensive magnitudes having the property of additivity and homogeneity. Since virtually all of Kant's arguments for the intuitions of space and time parallel each other, we will stick with time as our example. In the fourth argument of time, Kant writes: "Time is no discursive or, as one calls it, general concept, but a pure form of sensible intuition. Different times are only parts of one and the same time" (A31-32/B47). This argument presents an extensive, linear, and additive model of time, in which particular measures of time (seconds, minutes, months, years) are the units that add up to give us a complete and determinate image of time. As Zinkin maintains, this dimension of time allows for the application of determinate concepts that yield determinate judgments and the cognition of objects. In the fifth argument of time, however, Kant writes:

The infinitude of time signifies nothing more than that every determinate magnitude of time is only possible through limitations of a single time grounding it. The original presentation, time,${ }^{13}$ must therefore be given as unlimited. But where the parts themselves and every magnitude of an object can be determinately represented only through limitation, there the entire presentation cannot be given through concepts (for then the partial presentations precede) but their immediate intuition must be the ground. (A32/B47-48, emphasis added $)^{14}$

This argument has an important connection with Kant's analysis of intensive magnitudes, which supports the presence of a pure concept of "limitation" that is joined with the pure concepts of "reality" and "negation" under Quality. ${ }^{15}$ Since any sensation can be represented on a continuous scale increasing from or decreasing to zero, what is required is a pure concept of the understanding that limits the flow of sensations so that a determinate object can emerge, rather than simply "reality" and "negation" (which indicate the presence or absence of a sensation). In terms of temporality, however, Kant says that "space and time are quantum continua, be-

\footnotetext{
${ }^{11}$ Zinkin, pp. 140-41.

${ }^{12}$ Ibid.

${ }^{13}$ Emphasis in the original text (B edition).

${ }^{14}$ Throughout this passage, "representation" is Guyer's rendering of Vorstellung.

${ }^{15}$ See A80/B106. This point is observed by Guyer in Kant, p. 104.
} 
cause no part of them can be given except as enclosed between boundaries (points or instants), thus only in such a way that this part is again a space or a time" (A169/ B170). This means that neither space nor time is exhausted by the successive multiplication of particular spaces and times. While spaces and times can be divided up into discrete units and then added together to form homogenous wholes, this does not exhaust what space and time in fact are, for the intensive dimensions both of space and time, as "flowing" magnitudes, are not simply the sums of discrete parts but rather make possible the extraction of discrete measures of value by limiting the flow in various ways.

In the third Critique Kant observes that the imagination and the understanding enter into a relation that is not conducive to the direct application of determinate concepts to the manifold. As Zinkin argues, ${ }^{16}$ when what is exhibited (dargestellt) to the subject is something that either exceeds or falls short of a presentation (Vorstellung) within an extensive form of time, the imagination and the understanding enter into a free play, in which what is apprehended cannot be thought by means of a concept. When what is apprehended by the subject comes under an intensive form, the understanding finds nothing to be the object of its synthesis since there are not discrete parts to be unified but only a "flow," that is, an enduring and continuous multiplicity that is already integrated prior to the understanding's synthetic activity. It is at this point that the imagination is freed from its determinative relation with the understanding, or as Kant says, it is here that "the understanding serves the imagination rather than vice versa" (5:242). As Kant shows in the Subjective Deduction (on the "synthesis of recognition in the concept"), in order to produce a determinate cognitive judgment the understanding must be able to recognize that what is presented is the same as it was just prior (A103). But this is possible, as Zinkin argues, only under an extensive form of time, where a presentation (Vorstellung) is a distinct and absolute unity contained in the original moment in which it is apprehended. As Kant observes, if in mathematics the numbers that one were to add up were not presented as distinct unities, but were rather to merge or overlap with one another, then there would be no unity as the result of a synthesis and hence no possibility of applying the concept of their sum. Yet when the imagination is freed from the bonds of the understanding, this is precisely what the former does, namely, to produce presentations without distinction, blending and merging them into an overlapping intensive flow which the understanding, by the very nature of its activity, cannot synthesize through a concept. As such an intensive magnitude, this streaming of presentations is not measured in successive moments but rather through degrees, durations, accelerations and/or decelerations.

\section{INTENSIVE FORMS, THE FREE IMAGINATION, AND JUDGMENTS OF TASTE}

Zinkin argues that the imagination operates with such intensive intuitions when we make judgments of taste. What is the form of this intensive flow of exhibitions 
(Darstellungen)? On Zinkin's account, we can get a sense for this non-successive form of temporality by drawing an analogy with clock time. Just as one clock measures time by quantifying durations into seconds, minutes, and hours, what is needed is a another clock to observe whether the time within that clock time is accelerating or not. But this will only tell us that the two clocks exhibit either a difference or sameness in their rate of speeds; it will not give us a standard by which to measure it. There are two "times" needed, so to speak, in order to compare the rate of change between discrete measures of time such as seconds, minutes, or hours. We can also carry this example a bit further. If we wanted to tune two clocks to the exact same time, we would need a different standard by which to sync them up, that is, we would not be able to simply presuppose that one of them is the correct measure without another more basic orientation. In order to make them exact, we would require that the second-hand of each clock hit the one-second mark at the same time. But in order for this to be possible, we must have a form of time that is not simply defined by a succession of discrete moments but is rather continuous and integrated with itself.

This example also illustrates another point, namely, that intensive time can be used to reflect upon the more ordinary, chronological, or successive form of time. As in our example, we are brought before an originary integration of parts rather than a mere succession of discrete parts. And as an integration, this form of time provides the measure of change only in relation to itself, not as a measure of change that is understood as a relation between two self-identical and self-subsistent unities. ${ }^{17}$ In any case, Zinkin argues that this intensive form of time is what the imagination enters into-or perhaps more boldly creates, as I will suggest—when making a judgment of taste, in which, as Kant says, "what matters is what I do with this presentation within myself, and not the respect in which I depend on the object's existence" (5:205). It is here, as Zinkin writes, that "the imagination is free to play with time" 18 since time is here not composed of absolute and discrete parts but rather presented in a continuous unity that is nevertheless also a multiplicity of durations, gradations, degrees, accelerations, and diminutions. Indeed, since the understanding is only able to apply concepts to the manifold as it is presented under an extensive form of intuition, the imagination's freedom from the determinate laws of the understanding, which provide normative rules by which the manifold is organized into objects, creates the conditions under which the mind is able to

\footnotetext{
${ }^{17}$ On this point, Zinkin could have shown that Guyer's worry—namely, that Kant's analysis of intensive magnitudes is of empirical rather than a priori origin, and therefore has no place in grounding synthetic a priori principles of determinate judgment - while perhaps represents a problem within the context of the first Critique alone, is ill-founded when the larger architectonic is considered as a whole. Thus Zinkin writes: "This 'other time,' which can be said to be what is used to reflect upon the first measure of time, is what I am calling an intensive form of time, since, by means of it, one can measure the degree to which what is apprehended in extensive time takes up time. In other words, this form is what makes possible the intuition of intensive magnitudes" (Zinkin, p. 149). For a greater detailed discussion of the a priori structure of intensive magnitudes, see Marco Giovanelli's excellent monograph Reality and Negation: Kant's Principles of Anticipations of Perception (New York NY: Springer, 2011).

${ }^{18}$ Zinkin, p. 149.
} 
reflect on the processes by which experience is constituted by flows of sensations from which objects are derived.

Of course, the major difference between intensive ordering in the first and third Critiques is that intensive magnitudes in the first Critique refer to a measure with respect to the sensation that is tied to a determinate object, while in the third Critique the intensive order that forms the basis for aesthetic judgments of taste are an exhibition (Darstellung) of the subject's experiencing of her own mental state in the feeling of a pleasure or displeasure. Kant's move away from the determinate legislation of the understanding toward the independence of the power of imagination in the third Critique is decisive since it is because the judgment of taste makes no claim about the existence of determinate objects that it provides the transcendental condition for reflection on what the imagination is exhibiting. To be sure, if all judgments were concerned solely with the determining of objects, there would be no moments in which the subject could reflect on the processes by which objects are constituted. Now, in his discussion on the Ideal of Beauty, Kant offers a description of this difference in forms of judgment as well as a description of the process by which the imagination exhibits an intensive presentation and reflects on it. The following passage from Kant is worth quoting at length:

Notice how in a manner wholly beyond our grasp our imagination is able on occasion not only to recall, even from the distant past, the signs that stand for concepts, but also to reproduce an object's image and shape from a vast number of objects of different kinds or even of one and the same kind. Moreover, all indications suggest that this power, when the mind wants to make comparisons, can actually proceed as follows, though this process does not reach consciousness: the imagination projects, as it were, one image onto another, and from the congruence of most images of the same kind it arrives at an average that serves as the common standard for all of them. For instance: Someone has seen a thousand adult men. If now he wishes to make a judgment about their standard size, to be estimated by way of a comparison, then (in my opinion) the imagination projects a large number of the images (perhaps the entire thousand) onto one another. If I may be permitted to illustrate this by an analogy from optics: in the space where most of the images are united, and within the outline where the area is illuminated by the color applied most heavily, there the average size emerges, equally distant in both height and breadth from the outermost bounds of the tallest and shortest stature; and that is the stature for a beautiful man. (The same result could be obtained mechanically, by measuring the entire thousand, adding up separately all their heights and their breadths (and thicknesses) by themselves and dividing the sum by a thousand. And yet the imagination does just that by means of a dynamic effect arising from its multiple neapprehension of such shapes on the organ of inner sense). $(5: 233-34)^{19}$

Kant's comparison here between the intensive activity of the imagination and the synthetic activity of the understanding illustrates a number of points. First, the imagination exhibits a genuinely creative capacity when it is no longer bound to the rules of the understanding. Rather than simply calculating an average, a process that would require the successive addition of many figures, the imagination instantaneously

${ }^{19}$ Cf. Zinkin, p. 153. 
compounds its images into an intensive unity from which an average emerges and that forms the basis by which judgments about the individuals can be made. On this score, the work of the imagination, then, can be characterized as creating an intensive unity that can serve as a ground of the measures that can possibly follow from it.

Furthermore, the ideal that emerges does not necessarily resemble any single individual in the group, i.e., the ideal does not represent any one member but is only an average of them when taken as an integrated multiplicity. What is created by the imagination is therefore not a presentation (Vorstellung), nor is it based on any determinate presentation. It is rather an ideal to which individuals are approximated and judged accordingly. This is a unity from which rules for making judgments are generated. Since here the imagination is free from the synthetic activity of the understanding, it is not strictly bound to rules that would otherwise already be in play. What Kant illustrates in his analysis of the ideal of beauty, then, is that in its freedom from the understanding, the imagination exhibits the possibility of integrating past presentations into an intensive whole and exhibiting (Darstellung) them as prior to their determination under a concept, from which a comparison arises that does not depend on any recognition through a concept. It rather depends upon an a priori intensive form of intuition that makes possible the genesis of rules rather than a strict dependence on prior rules that would otherwise subsume the subject's presentations under determinate concepts.

When we consider Kant's remark that reflective judgment is a use of judgment that seeks to discover a concept for a particular exhibition (Darstellung), ${ }^{20}$ which contrasts with determinate judgment (i.e., a use of judgment that is simply the correct selection and application of a concept that the understanding already has) and we combine that remark with his analysis of the ideal of beauty, where the imagination unites various presentations into an intensive form and exhibits them for the mind, what we find is an account of concept formation (and not just mere selection and application) in which the imagination compares given presentations with one another and with the subject's cognitive powers. Here the imagination enters into an intensive relation with the intuitions the subject apprehends, and rules can be derived in the manner of Kant's quote above (5:233-34). As Zinkin observes, the concept that is supposed to result from this comparative reflection ${ }^{21}$ would then, only after, universally apply to our presentations. ${ }^{22}$

Once it goes this far, however, and the concept is put into play along with other concepts into a determinate matrix of understanding, then the concept enables recognition and determinate cognitive judgment. But with regard to judgments of taste, as Zinkin observes, when the imagination is no longer in the service of supplying concepts for the understanding, what emerges when the imagination enters into the intensive relation that Kant outlines in his analysis of the ideal of beauty is an aesthetic normative idea, which as Zinkin says is "an intensive image that is the

\footnotetext{
${ }^{20}$ See Kant's First Introduction to the Critique of Judgment, 20:211.

${ }^{21}$ In Kant and the Capacity to Judge (Princeton NJ: Princeton Univ. Press, 2001), Beatrice Longuenesse calls this a "universalizing comparison" (p. 116).

${ }^{22}$ Zinkin, p. 154.
} 
work of the imagination alone." ${ }^{23}$ As Kant writes, "It is the image for the entire kind, hovering between all the singular and multiply varied intuitions of the individuals, the image that nature used as the archetype on which it based its productions within any one species, but which it does not seem to have attained completely in any individual. The standard idea is by no means the entire archetype of beauty within this kind, but is only the form that constitutes the indispensible condition of all beauty" (5:234-35). This means that the aesthetic standard idea is not based on concepts that would direct the subject to recall previous apprehensions of beauty as recognitions but is the product of the imagination's unified apprehension of presentations overlapping into one singular and intensive whole. And just as intensive magnitudes in the first Critique provided the subject with a ground from which values can be derived, so here the intensive aesthetic presentation allows the subject to reflect on the form of this subjective presentation's variety of possible forms. As Zinkin aptly observes, "terms describing a beautiful object as having a richness or depth attest to the intuitive correctness of Kant's view that a beautiful object is one that enables the mind to find multiple forms in the same object." ${ }^{24}$

The imagination's activity of creating and reinforcing this intense image evades the understanding's attempts at synthesizing it into a successive form of time. Since the imagination is here running the show, so to speak, this opens the door for free reflection on the object of beauty. Yet it is obviously not the case that the subject somehow enters into a timeless relation with beauty when a judgment of taste (or for that matter, a judgment of the sublime) is produced. What, then, is the a priori reflective form of time in which the understanding and imagination enter into a harmonious relation that is precisely not one of determinate and objective cognition, but rather one of intensive reflection on the exhibitions of the imagination itself?

\section{INTENSIVE TIME AND SENSUS COMMUNIS}

Thus far we have found, with the help of Zinkin's analysis, that what distinguishes cognitive judgments from aesthetic judgments is the intensive form in which the imagination presents its apprehensions as an extensive manifold (Mannigfaltigkeit) in objective cognition, and as an intensive multiplicity (Vielheit) in aesthetic cognition. ${ }^{25}$ The final stages of Zinkin's argument consist of her attempts to establish the sensus communis as the a priori form of intuition that makes possible the intensive forms created by the imagination. Her argument is based on Kant's description of the sensus communis as a transcendental condition of the possibility of communicating

\footnotetext{
${ }^{23}$ Ibid.

${ }^{24}$ Ibid., p. 156.

${ }^{25}$ In his Imagination and Interpretation in Kant (Chicago IL: Univ. of Chicago Press, 1990), Rudolf Makkreel clearly outlines Kant's distinction between Mannigfaltigkeit and Vielheit. I would furthermore argue that this distinction maps quite neatly onto Kant's analysis of extensive and intensive magnitudes. Makkreel writes: "In logical or mathematical comprehension the content of sense is regarded as a manifold, i.e., a complex of temporally determined parts. In aesthetic comprehension, by contrast, the content of sense is regarded as a multiplicity of indeterminate parts of a whole. The unity of the former must be inferred by means of a concept and involves the objective progress of the imagination. The unity of the latter can be instantaneously comprehended in the subjective regress of the imagination" (p. 75).
} 
sense (Sinn), and so therefore, on her account, represents a form of sense (and perhaps more importantly, grounds the very normativity of judgments of taste). While it is indeed true that for Kant the sensus communis is a subjective sense possessed by each of us that enables communication, I would like to ask whether the sensus communis, as Kant says, must remain a condition that must simply be presupposed in all judgments of taste, or whether there are any resources in Kant that can provide us with a genetic account of the sensus communis, i.e., an account that grounds our "sense of community" 26 in an intensive form of intuition.

In a striking passage that seems to raise a similar difficulty, Kant draws a relevant distinction in section 22 by asking whether the sensus communis is really just a mere presupposition demanded by reason to make taste possible, or whether it is in fact an actual capacity given in human nature that conditions the possibility of experience in general. He writes,

That we do actually presuppose this indeterminate standard of a common sense is proved by the fact that we presume to make judgments of taste. But is there in fact such a common sense, as a constitutive principle of the possibility of experience, or is there a still higher principle of reason that makes it only a regulative principle for us [in order] to bring forth in us, for higher purposes, a common sense in the first place? In other words, is taste an original and natural ability, or is taste only the idea of an ability yet to be acquired and [therefore] artificial, so that a judgment of taste with its requirement for universal assent is in fact only a demand of reason to produce such agreement in the way we sense? In the latter case the ought, i.e., the objective necessity that everyone's feeling flow along with the particular feeling of each person, would signify only that there is a possibility of reaching such agreement; and the judgment of taste would only offer an example of the application of this principle. $(5: 240)$

Given that this passage occurs after Kant's descriptions of the sensus communis in section 20, which I have cited as support for my view, it could be argued that what Kant writes in those previous passages could not yet be taken as support for a grounding of the sensus communis in an operation of the mental powers that would answer the question later posed by Kant in section 22 just cited. Hence without the proper qualification that takes Kant's own section 22 question into account, the argument on offer in this paper would remain incomplete. Just prior to this passage, Kant had argued that judgments of taste are possible only if there is a common sense, and that the distinctiveness of judgments of taste rests on their being grounded on a strictly aesthetic common sense, one that is not dependent on the determinate legislative arrangements of the faculties that obtain in either epistemic or practical judgment. In the passage just quoted, however, Kant seems to suggest that the simple fact that we make aesthetic judgments of taste is not sufficient to prove that common sense has been established or does in fact exist. As Fiona Hughes suggests, Kant's worry seems to be that, in the end, judgments of taste may turn out to be disguised rational

\footnotetext{
${ }^{26}$ Makkreel makes clear that by "common sense" Kant has in mind the German ideal of a Gemeinsinn, or "communal sense," which connotes an integrated sense of community that precedes any individual members or collection of individual members. It is a social body that is integrated and intensive rather than merely collective and extensive in nature (Imagination and Interpretation in Kant, p. 64).
} 
judgments based on principles of reason, rendering taste an "artificial" ability that reason aims to bring about for its own purposes. If true, this would thus undo any purported need for a critique. ${ }^{27}$ Unfortunately, having raised this important question, Kant's next move is entirely deflationary; he neither develops the point nor does he even acknowledge its radical nature: "These questions we neither wish to nor can investigate at this point. For the present our task is only to analyze the power of taste into its elements, and to unite these ultimately in the idea of a common sense" (5:240). At this point Kant simply moves on, leaving commentators to make of this passage what they will. ${ }^{28}$ Kant's position thus appears to be essentially incomplete.

Anthony Savile has perhaps gone the farthest on this issue by arguing convincingly that the Critique of Aesthetic Judgment presents a two-fold structure that first presents reflections on taste's relationship to cognition. In later sections from section 22 onwards, Kant is concerned primarily with the acquisition of taste and its cultivation and habituation. Thus it is argued that we should read the structure of the Critique as first concerned with our capacity to take universal subjective pleasure in things, in the text's earlier discussions of taste's relationship to cognition, while the argument is later concerned with our actual ability to do so. ${ }^{29}$ As Savile suggests, for example, we are born with a capacity to swim, even though that ability is not acquired without the requisite training to develop it. Once developed over time, we might exercise that ability or we might not. But without regular practice or at least periodical exposure to objects and events that would potentially occasion their development, both the capacities we are given and the actual abilities we would otherwise cultivate can fade or grow rusty. On this view, our capacities are nevertheless initially given, while the actualization of those capacities remains a matter for individual practice. Savile thus seeks to bridge the dilemma presented in the passage just quoted, where an inchoate capacity for subjectively universal aesthetic reflection is given in human nature, while an actual ability to employ it requires an exposure to beautiful objects and the aesthetic judgments of others, the cultivation of which it is reasonable to expect from a subject endowed with such capacities. As Savile argues elsewhere, "common sense is something to which we aspire as well as something that we need to possess if aesthetic experience is to be a possibility at all. ${ }^{{ }^{30}}$ On this view, contra Hughes, the issue is not framed as a worry that aesthetic judgments might in the end be disguised determinate rational

\footnotetext{
${ }^{27}$ See Fiona Hughes's commentary Kant's Critique of Aesthetic Judgment: A Reader's Guide (New York NY: Continuum, 2010), pp. 72-74.

${ }^{28} \mathrm{Hughes}$ argues that at this point Kant simply assumes that taste is an original and natural faculty founded in human nature (Reader's Guide, p. 74). By contrast, in his Kant on Judgment (New York NY: Routledge, 2007), Robert Wicks argues that "common sense - the capacity to experience the optimal free play of the harmony of the faculties without any admixture of interest-is only an ideal norm (bloße idealische Norm) that regulates our efforts to make judgments of pure beauty" (p. 84). Wicks seems to leave untouched the problem concerning in what sense Kant intends this, whether as intending that judgments of beauty in the end appear to be disguised rational judgments or if some other sense of "ideal" is intended. To be sure, however, the context of Wicks's discussion seems to suggest a much looser and less technical sense of that term.

${ }^{29}$ Anthony Savile, Aesthetic Reconstructions: The Seminal Writings of Lessing, Kant, and Schiller (New York NY: Blackwell, 1987), pp. 189-91. See also Savile's Kantian Aesthetics Pursued (Edinburgh: Edinburgh Univ. Press, 1993), pp. 38-39.

${ }^{30}$ Savile, Kantian Aesthetics Pursued, p. 38.
} 
judgments, but rather, less strongly, as the reasonable demand for a subject to realize her various potentials given by her natural capacities.

Textual support for this position is found in the various passages that Kant refers to a cultivating of taste, which suggests a forming or molding of taste, or an adaptation of the subject to taste requisite for making valid aesthetic judgments. For instance, Kant gives the example of a young poet who cannot be convinced to abandon his persuasion that a certain poem of his own creation is beautiful. Neither the judgment of his friends nor of any other audience can bring him to abandon his view. It is only after his judgment is sharpened by practice that he is able to voluntarily depart from his previous assessment, that is, as his taste is gradually molded to what he now sees as a subjectively universal validity in the judgment $(5: 282) .{ }^{31}$ The subjective fact of the realization actualizes a capacity within the young poet, raising a dormant capacity to an actual ability. Kant's example thus supports the view that distinguishes a capacity for aesthetic taste from its cultivated ability since any actual development of one's sound aesthetic judgment requires an a priori capacity to stand in the place of others and stake a subjectively universal aesthetic claim, the validity of which rests only on the universal communicability of feeling presupposed as its background condition.

More strongly, the fact that we can cultivate taste by prior examples, relevant experiences, and rational deliberation provides support for the view of the sensus communis that I am defending here, since it is clear from Zinkin's analysis that the intensive forms generated by the imagination provide a genetic account of the rules for reflective judgments of beauty, thus supporting the subject's cultivation of taste, while the normativity of those rules is grounded in the sensus communis, thus supporting the presence of a given capacity in the subject for normatively guided aesthetic reflection. As mentioned earlier, Kant describes the sensus communis as "the effect arising from the free play of the cognitive powers," which-given the issues raised by Kant in section 22, and bolstered by the corresponding distinction between capacity and actual ability-indicates that the sensus communis is not simply what is presupposed in judgments of taste as a mere background condition but also virtually produced or generated by the imagination in its activity of reflection. In Savile's terms, it is the actualization of an inchoate capacity of universally communicable though only subjectively valid reflective experience. Pushing further than both Savile and Zinkin, the deeper question animating the present paper concerns the very feeling that allows a merely given capacity to be actualized, and the forms of sensibility by which that feeling is presented. In the remainder of the paper, then, I would like to offer a solution to the problem of the genesis of the sensus communis, whether thus considered in either of its manifestations as suggested by Savile as an inchoate capacity or an actual ability. My argument is that it resides within an intensive form of time in which the basic moments of temporality, i.e., past, present, and future, are integrated and reflect one another, in contrast with an extensive form of time, in which past, present, and future are represented as independent moments

\footnotetext{
${ }^{31}$ See also Kant, Critique of the Power of Judgment, 5:283, 5:284, 5:286.
} 
of time. Of course, since Kant does not speak about the sensus communis in this way, some further interpretive leeway must be granted.

In his analysis of the "regress of the imagination" in the experience of the sublime in Kant, Makkreel shows how an intensive form of time ${ }^{32}$ emerges when the imagination reaches its maximal limit, that is, when the imagination approaches "the absolutely great" as an idea of reason. Makkreel observes that the imagination's successive operations are interrupted, and a "regress" is instituted that makes the intuition of coexistence possible. ${ }^{33}$ Kant writes,

Comprehending a multiplicity in a unity (of intuition rather than of thought), and hence comprehending in one instant what is apprehended successively, is a regression that in turn cancels the condition of time in the imagination's progression and makes simultaneity intuitable. Hence, (since temporal succession is a condition of the inner sense of an intuition) it is a subjective movement of the imagination by which it does violence to the inner sense, and this violence must be the more significant the larger the quantum is that the imagination comprehends in one intuition. . . . And yet this same violence that the imagination inflicts on the subject is still judged purposive for the whole vocation of the mind. (5:258-59, emphasis added)

Now Kant's most extended treatment of the sensus communis comes just before his treatment of the experience of the sublime. Kant does in fact describe the sensus communis as an "idea," 34 a term that for Kant denotes a concept of reason that is not an object of knowledge. This of course makes perfect sense within the broader Kantian system since the sensus communis is integrated and intensive. As such, it cannot be presented through the extensive forms of space and time that are required by the understanding in its synthetic activity, which is a condition for knowledge. Therefore, to borrow a phrase from the first Critique, the sensus communis cannot properly speaking be known but only thought. Yet in the third Critique, Kant opens the door to the possibility that the sensus communis be apprehended by the subject in a way that is otherwise than cognitive, i.e., it is exhibited reflectively as a ground of the normativity of judgments of taste.

In the experience of beauty, a subject renders a judgment of taste on the condition that, in Kant's words, we "put ourselves in the position of everyone else, merely by abstracting from the limitations that may happen to attach to our own judging" $(5: 294)$. Here the sensus communis comes before the subject not directly but only reflectively. Of course, this feeling of community with others that resides in the subject is intensive and not extensive in form, i.e., it is not a feeling that the subject is one subject in a collection of subjects, but rather the subject senses herself as integrated within a shared community of reflective subjects. In short, it is this sense of the integration of subjects that is the idea of the sensus communis itself. Yet when

\footnotetext{
${ }^{32}$ Makkreel does not refer to this form of time as intensive, but it is clear that given our analysis above this is indeed an accurate (and more importantly, Kantian) characterization of the form of time that Makkreel seeks to disclose in his analysis.

${ }^{33}$ Makkreel, Imagination and Interpretation in Kant, p. 73.

${ }^{34} \mathrm{Cf}$. Section 20, which is entitled "The Condition for the Necessity Alleged by a Judgment of Taste Is the Idea of a Common Sense" (5:237).
} 
the subject places herself within the reflective judgment of others, she only does so by presupposing a model of time itself that is not a linear succession of discrete "now" points or moments but an integrated prior unity in which past, present, and future reflect one another to create a sense of community in which the lives of the individual subjects that inhabit this space are oriented in absolutely fundamental ways. As Makkreel argues, while the mathematical or linear form of time is "annihilated" in the imagination's encounter with an idea of reason in the sublime, this does not amount to a full blown annihilation of time itself "but merely suggests the possibility of negating" 35 the strictly chronological conception of "clock time," which is the form of time that, at least in the broad sweep of Western culture, has come to supplant the more originary intensive or flowing sense of temporality.

Within the reflective moment in which the imagination encounters an idea of reason at its limits, as Makkreel argues, the progressive and linear model of extensive time, which makes a mathematical and scientific reading of nature possible, is interrupted (or at least altered), and the subject now intuits its multiplicity of presentations comprehensively rather than successively. ${ }^{36}$ This is no less true for the subject's contemplation of the idea of the sensus communis. This sense of community presupposes as its ground a temporal orientation in which past, present, and future are integrated and mutually reinforcing. The intuitive correctness of this view of the sensus communis is supported by the fact that every community, i.e., every group of individuals who share a sense of identity and pursue common goals and fundamental ways of orienting daily living, share an integrated sense of history, of culture, and of futural orientation that are not discrete moments in time but rather coalesce into a shared sense of life. Such an analysis of these facts reveals, then, that the "sense of community" that both enables the communication of the necessity of judgments of beauty and grounds their normativity, is itself grounded in an intensive form of time in which a people's sense of community expresses an integrated and shared sense of past, present, and future.

This intensive sense of time is one in which, by reflecting on that aspect of time that exhibits itself as continuous and flowing, the subject is able to consider the ways in which the basic modes of temporality relate to one another. For example, it is easy to see in what ways the past conditions the present and the future. The choices I have made in the past tend to determine my present situation as well as the future that I perceive for myself. Yet a fully integrated sense of temporality is one in which, for instance, the present conditions the past, or the future conditions the present. However, without getting too far afield, the results of our analysis are highly suggestive for further reflections on the nature of this sense of integrated and intensive temporality, a theme that has occupied post-Kantian philosophers all the way up to the present.

As regards the sensus communis itself, this integrated and intensive sense of time obtains on a social level prior to an individual level (which implies, in the first instance, the priority of reflective thought over determinate cognition, at least for

\footnotetext{
${ }^{35}$ Makkreel, Imagination and Interpretation in Kant, p. 73.

${ }^{36}$ Ibid., p. 74.
} 
human beings). As I have argued, it is this sense of time that informs the sensus communis, which allows a collective body to form a coalition (rather than a mere aggregate ${ }^{37}$ ) of subjects who share an orienting sense of history and culture, rather than a collection of individuals who merely "contract" with one another with the aim of pursuing predetermined self-interests. While a proper justification of the following point exceeds the limits set out by the aims of the present analysis, the idea of the sensus communis as social priority consequently produces a very different form of subjectivity than that which follows upon a contractarian view of social construction. The question here would be one of exploring the meaning of what we might call intensive or communal subjectivities as distinct in kind from what we might call extensive or atomistic subjectivities. ${ }^{38}$

\section{CONCLUSION}

Through an analysis of extensive and intensive magnitudes, the freedom of the imagination and judgments of taste, and the relation between the intensive form of time and Kant's idea of the sensus communis, I have argued that we can account for the temporal genesis of the sensus communis by showing that it resides within an intensive form of time in which a people's sense of past, present, and future are fully integrated and mutually reinforcing, thereby orienting a general sense of life. We have seen that since the sensus communis is an idea of reason, when the imagination encounters this idea it enters into an intensive form of time that makes simultaneity intuitable. This simultaneity is informed by a sense of temporality in which the past, present, and future are no longer linearly represented as discrete and absolute unities, but are rather intensively integrated into a multiplicity in which the parts are fully harmonized and mutually reinforcing. On this analysis, the sensus communis is not just immediately presented to the subject as that which must be presupposed in order to ground judgments of taste, but is exhibited reflectively to the subject when she encounters the sensus communis as an idea of reason.

Finally, by grounding the sensus communis within this intensive form of time, we can meet Kant's critical injunction that all mental activity, including the subject's reflective encounter with the sensus communis as an idea of reason, must be shown to have a temporal form as a condition for their possibility. In this way the sensus communis becomes more than that which is simply presupposed in judgments of taste but is also a general orientation toward life that resides in an intensive form of time that grounds its very genesis. What the sensus communis ultimately expresses, then, is that what is needed for a genuine "sense of community" to be possible is less of an extensive collection of individuals and more of an integrated and intensive coalition of individuals who share a sense of time in which past, present, and future, i.e., if I may be permitted, history, culture, and social destiny, are fully integrated

\footnotetext{
${ }^{37}$ This terminology is borrowed directly from Kant in the first Critique (B201n).

${ }^{38} \mathrm{On}$ this point, a distinction that is perhaps relevant and worth exploring would be Kant's distinction between the person and the human being in the analysis of the dynamically sublime (Critique of the Power of Judgment, section 28, specifically 5:261-2).
} 
and provide a general orientation for the feeling of life. ${ }^{39}$ It is an intensive form of temporality that makes possible this integrated sense of time, thereby generating this general orientation of living.

${ }^{39}$ Makkreel gives much weight to the feeling of life in Kant's overall philosophy (Imagination and Interpretation in Kant, especially chap. 5). Here Makkreel argues that "indeed it is possible to interpret the overall structure of The Critique of Judgment as one whereby the idea or sense of life is gradually explicated. Aesthetic judgment is rooted in a subjective feeling of mental life; teleological judgment articulates individual objective forms of organic life" (p. 89). 